\title{
Analisis Kinerja Prosesor terhadap Proses Overclocking dan Downclocking
}

\author{
Azhar ${ }^{*}$, Firdaus $\mathrm{H}^{2}$ \\ ${ }^{1,2}$ Program Studi Teknik Elektro Fakultas Teknik Universitas Muhammadiyah Makassar \\ e-mail: azhar_one@ymail.com
}

\begin{abstract}
The rapid development of technology causes hardware technology is also experiencing rapid pekembangan, so that the existing hardware to be fast using, Computers is an electronic device capable of performing several tasks as follows, receive input, process the input earlier in accordance with the program, save the commands and the results of processing. The purpose of this study is to show how much influence is given by overclocking and downclocking process to processor performance, to know the effect on the working temperature generated and the power used from the process. This research method is data analysis with tools that have been prepared. The result of this research is by application of benchmark of synthesis, graph of which shows that the higher the value hence the better its performance, except in Super Pi application which uses second time unit (s) where less time required in test indicate optimal processor performance, to overcome from the need for high computing and so as not to rush to upgrade hardware and also to save more cost in hardware upgrade. The conclusion is the frequency of downcloking generated by $1000 \mathrm{MHz}$, standard frequency $3000 \mathrm{MHz}$, Overclocking frequency of $3750 \mathrm{MHz}$, unstable system, with the overclock system will be unstable until lag / hang unstable system occurs at frequencies above $3.75 \mathrm{GHz}$.
\end{abstract}

Keywords: frequency; processor; temperature; power; overclocking; downclocking

\begin{abstract}
Abstrak
Pesatnya perkembangan teknologi menyebabkan teknologi hardware juga mengalami pekembangan yang pesat, sehingga hardware yang ada menjadi cepat using, Komputer adalah suatu alat elektronik yang mampu melakukan beberapa tugas sebagai berikut, menerima input, memproses input tadi sesuai dengan programnya, menyimpan perintah-perintah dan hasil dari pengolahan. Tujuan penelitian ini adalah menunjukkan seberapa besar pengaruh yang diberikan oleh proses overclocking dan downclocking terhadap kinerja prosesor, mengetahui pengaruh terhadap suhu kerja yang dihasilkan serta daya listrik yang digunakan dari proses. Metode penelitian ini merupakan analisa data dengan alat yang telah disiapkan. Hasil penelitian ini adalah dengan aplikasi benchmark sintesis, grafik yang terpampang menunjukkan bahwa semakin tinggi nilainya maka semakin baik kinerjanya, kecuali pada aplikasi Super Pi yang menggunakan satuan waktu second (s) dimana semakin sedikit waktu yg dibutuhkan dalam ujicoba menandakan kinerja prosesor optimal, untuk mengatasi dari kebutuhan akan komputasi yang tinggi dan agar tidak terlalu terburu-buru meng-upgrade hardware dan juga untuk lebih menghemat biaya dalam meng-upgrade hardware. Kesimpulan nya adalah Frekuensi downcloking yang di hasilkan sebesar $1000 \mathrm{MHz}$, Frekuensi standar $3000 \mathrm{MHz}$, Frekuensi Overclocking sebesar $3.750 \mathrm{MHz}$, sistem tidak stabil, dengan dilakukannya Overclock sistem akan tidak stabil hingga terjadi lag / hang sistem tidak stabil terjadi pada frekuensi di atas 3,75 $\mathrm{GHz}$.
\end{abstract}

Kata kunci: frekuensi; suhu; daya; overclocking; downclocking

\section{Pendahuluan}

Komputer berasal dari bahasa latin computare yang mengandung arti menghitung. Komputer adalah suatu alat elektronik yang mampu melakukan beberapa tugas sebagai berikut: menerima input, memproses input tadi sesuai dengan programnya, menyimpan perintahperintah dan hasil dari pengolahan, menyediakan output dalam bentuk informasi. Tidak hanya perusahaan-perusahaan besar yang telah memanfaatkan komputer, perusahaan kecil pun telah 
mulai menerapkan komputerisasi untuk membantu produksi. Disamping itu komputer membantu manusia melakukan pekerjaan yang tidak mungkin bisa manusia lakukan, misalnya untuk menghasilkan pengukuran yang akurat dalam suatu penelitian ilmiah. Perkembangan komputer telah mempermudah manusia untuk melakukan komunikasi jarak jauh dengan biaya yang relatif murah, yaitu dengan adanya fasilitas internet. Hal menarik lagi adalah dengan adanya sarana multimedia pada komputer telah hadir suatu sarana hiburan yang relatif murah di rumah.

Penelitian ini akan melakukan proses overclocking serta downcloking terhadap prosesor. Hal ini merupakan tujuan dari proses overclocking serta downclocking, yakni untuk menghasilkan kinerja optimal pada kinerja prosesor. Terdapat beberapa pengertian yang biasa digunakan dalam hal pengubahan frekuensi prosesor dari keadaan standar. Dalam pengertian overclock adalah meningkatkan frekuensi kerja standar dari suatu prosesor sampai titik tertentu. Teknik overclocking yaitu mengubah pengaturan awal dari pabrikan agar didapat clockspeed yang lebih tinggi. Menurut Mueller (2012:124) overclock yaitu "set the processor speed to run faster than the rating on the chip", sedangkan menurut Wainner (2003:3) overclocking is the process of increasing the speed or clock frequencies of devices, such as processors, beyond their factory defaults. Maka overclock berarti melampaui kecepatan clock, agar komputer berjalan lebih cepat dengan default kecepatan komputer standar atau yang telah ditetapkan pabrikan. Jadi overclock adalah suatu cara untuk dapat memaksimalkan kinerja pada prosesor agar komputer dapat bekerja lebih cepat dari spesifikasinya atau yang diperoleh dari bawaan pabrik. Tujuannya bukanlah untuk mencari clockspeed setinggi-tinginya, tetapi untuk mencari clockspeed yang lebih tinggi dengan kinerja yang paling stabil. Overclocking juga bisa digunakan sebagai solusi bagi pembeli awal untuk menghemat biaya dalam mendapatkan komputer dengan performa yang lebih tinggi dari spesifikasi prosesor pada saat pembelian. Tujuannya pun bermacam-macam ada yang ingin meningkatkan kinerja komputernya tanpa perlu membeli perangkat baru terutama prosesor. Dalam penelitian ini khususnya kartu grafis, hasil akhir dari overclock sendiri adalah prosesor menjadi lebih panas dan konsumsi dayanya menjadi lebih besar. Uji coba yang dilakukan lebih mengarah kepada mild overclock, dengan komputer standar.

Sebaliknya downclock berarti menurunkan frekuensi kerja standar prosesor menjadi lebih rendah. Tujuannya sendiri adalah untuk mendapatkan prosesor yang lebih dingin dan lebih hemat daya. Dengan downclock pula, kebisingan yang dihasikan oleh fan prosesor dapat diminimalisir dengan mengatur perputaran fan prosesor supaya berputar lebih pelan karena prosesor tidak terlalu panas. Perangkat PC yang di-overclock sama saja dengan dipaksa melebihi kemampuan aslinya. Namun, overclock pada prosesor ini, selain membuat perangkat sistem menjadi tidak stabil dan dapat membuat kerusakan pada perangkat keras, terutama mainboard, hardisk, dan prosesor. Kualitas baik dan dapat diandalkan, motherboard yang bagus dengan $\mathrm{BIOS}$ yang lengkap. Untuk perangkat keras dengan kualitas memadai dan bagus untuk di-overclock tidak selalu berharga mahal. Kerusakan perangkat keras karena di-overclock terutama disebabkan oleh panas yang berlebih untuk menghindarinya banyak cara yang bisa dikerjakan misalnya memperbaiki sistem aliran udara dalam casing, memperbaiki heatsink $\mathrm{CPU} /$ chipset/VGA dengan cara mengganti dengan pendingin berkualitas yang sekarang banyak dijual di toko-toko komputer di Indonesia.

Komputer yang digunakan untuk pemakaian sehari-hari dan untuk jangka waktu panjang maka diperlukan ketelitian dalam mendapatkan pengaturan yang sesuai, karena teknik overclocking dapat mengakibatkan terjadinya system failure, error, sampai kerusakan permanen dari prosesor itu sendiri apabila tidak teliti dalam mengubah setingan pada BIOS (Basic Input Output Setting) (chip team). Mengingat betapa pentingnya pemahaman serta langkah-langkah akan proses overcloking serta downclocking terhadap prosesor maka penelitian ini dibuat untuk melihat proses overclocking dan downclocking pada Prosesor Amd AthlonTM II X2 250 (3 GHz).

\section{Metode Penelitian}

Penelitian ini menggunakan metode literatur yang mendukung, kemudian membuat tahap dari skenario pengujian dan melakukan ujicoba langsung dengan komputer yang ada dengan pengubahan variable prosesor melalui BIOS untuk mendapatkan frekuensi tertinggi dan terendah yang bisa diperoleh dari suatu prosesor, yang di uji dan frekuensi tertinggi yang bisa dicapai dimana sistem masih stabil lalu kemudian diputuskan interval frekuensi yang akan diuji coba. Tahap akhir baru menyimpulkan seberapa besar pengaruh overclocking dan 
downclocking terhadap kinerja prosesor. Ada beberapa hal yang perlu diperhatikan dalam melakukan overclock yaitu suhu dan tegangan. Dalam melakukan overclock, hal yang sering terjadi yaitu kenaikan suhu. Menurut Wainner (2003:13) "If core temperatures exceed normal operating specifications, the system can become unstable. Circuits can also be damaged during prolonged periods of intense heat', sehingga sistem pendinginan yang baik sangat diperlukan pada sistem komputer. Tegangan pada core processor juga perlu dinaikan agar kestabilan tetap terjaga sesuai dengan pendapat Wainner (2003:29) "Achieving stability at extended operating speeds often requires increasing voltage levels, and sustaining faster processor speeds can demand a greater core voltage".

Penelitian ini bersifat eksperimen, dimana pengertian eksperimen menurut adalah "observasi di bawah kondisi buatan (artificial condition) dimana kondisi tersebut dibuat dan diatur oleh si peneliti". Dengan demikian penelitian eksperimental adalah penelitian yang dilakukan dengan mengadakan manipulasi terhadap objek penelitian serta adanya kontrol Metode eksperimen yang digunakan pada penelitian ini adalah eksperimen sungguhan (true experiment) yaitu "Menyelidiki kemungkinan sebab-akibat dengan desain di mana secara nyata ada kelompok perlakuan dan kelompok kontrol dan membandingkan hasil perlakuan dengan kontrol secara ketat. Validitas internal dan eksternal cukup utuh." Berdasarkan pengertian yang telah dikemukakan, penelitian ini akan melihat kinerja prosesor setelah diberi perlakuan (treatment) yaitu overclock dan downclock dengan cara melakukan perubahan pengaturan kecepatan yang ada pada BIOS, dan melihat kinerja dengan aplikasi benchmark, tes dilakukan yaitu stressing test, real-life test. Analisis datanya berupa perhitungan kenaikan kecepatan awal dengan kecepatan setelah di overclock maupun downclock dalam persentase.

Peralatan yang digunakan pada penelitian ini terdiri atas perangkat keras dan perangkat lunak, sebagai berikut:

Tabel 1. Peralatan

\begin{tabular}{cccc}
\hline \multirow{2}{*}{ Perangkat Keras } & \multicolumn{3}{c}{ Perangkat Lunak } \\
\cline { 2 - 4 } & Benchmark Sintetis & Benchmark Real Life & Lainnya \\
\hline Komputer desktop & Super PI & Windows BOOT Timer & CPUID HWMonitor \\
& PC Mark 05 & Winrar & CinebenchR10 \\
\hline
\end{tabular}

Proses pengujian mengikuti alur sebagai berikut:

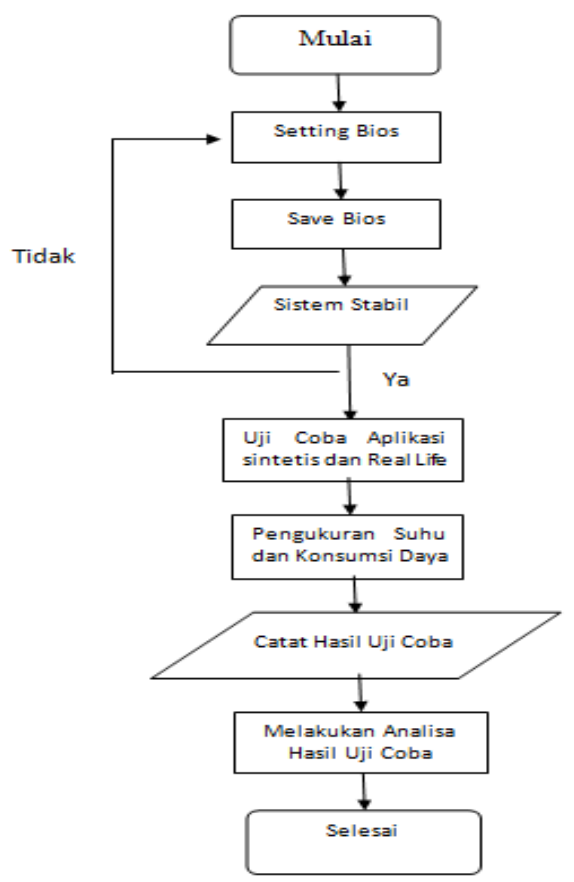

Gambar 1. Flowchart pengujian 


\section{Hasil dan diskusi}

Uji aplikasi Benchmark Sintesis untuk Super PI dapat dilihat pada gambar 2 perbandingan kinerja antara frekuensi standar dengan frekuensi pada saat downclocking dan overclocking.

\begin{tabular}{ccc}
\hline Percobaan & Frekuensi & Super Pi 1 M \\
\hline 1 & $1.000 \mathrm{MHz}$ & $1 \mathrm{~m}, 16.315 \mathrm{~s}$ \\
\hline 2 & $1.250 \mathrm{MHz}$ & $0 \mathrm{~m}, 59.951 \mathrm{~s}$ \\
\hline 3 & $1.500 \mathrm{MHz}$ & $0 \mathrm{~m}, 48.453 \mathrm{~s}$ \\
\hline 4 & $1.750 \mathrm{MHz}$ & $0 \mathrm{~m}, 41.793 \mathrm{~s}$ \\
\hline 5 & $2.000 \mathrm{MHz}$ & $0 \mathrm{~m}, 36.570 \mathrm{~s}$ \\
\hline 6 & $2.250 \mathrm{MHz}$ & $0 \mathrm{~m}, 32.467 \mathrm{~s}$ \\
\hline 7 & $2.500 \mathrm{MHz}$ & $0 \mathrm{~m}, 29.557 \mathrm{~s}$ \\
\hline 9 & $2.750 \mathrm{MHz}$ & $0 \mathrm{~m}, 27.674 \mathrm{~s}$ \\
\hline 10 & $3.000 \mathrm{MHz}$ & $0 \mathrm{~m}, 25.959 \mathrm{~s}$ \\
\hline 11 & $3.250 \mathrm{MHz}$ & $0 \mathrm{~m}, 24.367 \mathrm{~s}$ \\
\hline 12 & $3.500 \mathrm{MHz}$ & $0 \mathrm{~m}, 23.026 \mathrm{~s}$ \\
\hline
\end{tabular}

Gambar 2. Perbandingan kinerja dengan frekuensi standar pada desktop dengan aplikasi Super Pi

Perbandingan skor antara frekuensi standar dengan frekuensi pada saat downclocking dan overclocking pada PC Mark 05 untuk uji aplikasi Benchmark Sintesis ditunjukkan pada gambar berikut.

\begin{tabular}{ccc}
\hline Uji coba & frekuensi & Skor point \\
\hline 1 & $1.000 \mathrm{MHz}$ & 10942 \\
\hline 2 & $1.250 \mathrm{MHz}$ & 12275 \\
\hline 3 & $1.500 \mathrm{MHz}$ & 13605 \\
\hline 4 & $1.750 \mathrm{MHz}$ & 14910 \\
\hline 5 & $2.000 \mathrm{MHz}$ & 16207 \\
\hline 6 & $2.250 \mathrm{MHz}$ & 17535 \\
\hline 7 & $2.500 \mathrm{MHz}$ & 18555 \\
\hline 8 & $2.750 \mathrm{MHz}$ & 20155 \\
\hline 9 & $3.000 \mathrm{MHz}$ & 21455 \\
\hline 10 & $3.250 \mathrm{MHz}$ & 23456 \\
\hline 11 & $3.500 \mathrm{MHz}$ & 24112 \\
\hline 12 & $3.750 \mathrm{MHz}$ & 26180 \\
\hline
\end{tabular}

Gambar 3. Perbandingan kinerja dengan frekuensi standar pada desktop dengan aplikasi PC Mark 05

Hasil dari Aplikasi 3D 2001 pada uji aplikasi Benchmark Sintesis untuk perbandingan skor antara frekuensi standar dengan frekuensi pada saat downclocking dan overclocking ditunjukkan pada gambar berikut. 


\begin{tabular}{ccc}
\hline Ujicoba & Frekuensi & Waktu (S) \\
\hline 1 & $1.000 \mathrm{MHz}$ & 43,383 \\
\hline 2 & $1.250 \mathrm{MHz}$ & 40,951 \\
\hline 3 & $1.500 \mathrm{MHz}$ & 38,453 \\
\hline 4 & $1.750 \mathrm{MHz}$ & 36,793 \\
\hline 5 & $2.000 \mathrm{MHz}$ & 35,570 \\
\hline 6 & $2.250 \mathrm{MHz}$ & 34,467 \\
\hline 7 & $2.500 \mathrm{MHz}$ & 33,557 \\
\hline 8 & $2.750 \mathrm{MHz}$ & 31,674 \\
\hline 9 & $3.000 \mathrm{MHz}$ & 30,959 \\
\hline 10 & $3.250 \mathrm{MHz}$ & 29,367 \\
\hline 11 & $3.500 \mathrm{MHz}$ & 28,026
\end{tabular}

Gambar 4. Perbandingan kinerja dengan frekuensi standar pada desktop dengan aplikasi 3D Mark 2001

Perbandingan waktu kinerja antara frekuensi standar dengan frekuensi pada saat downclocking dan overclocking dalam uji aplikasi Benchmark Real Life untuk Windows Boot Timer dapat dilihat pada gambar 5.

\begin{tabular}{clc}
\hline Ujicoba & Frekuensi & Waktu (s) \\
\hline 1 & $1.000 \mathrm{MHz}$ & 67.56 \\
\hline 2 & $1.250 \mathrm{MHz}$ & 48.59 \\
\hline 3 & $1.500 \mathrm{MHz}$ & 43.25 \\
\hline 4 & $1.750 \mathrm{MHz}$ & 38.52 \\
\hline 5 & $2.000 \mathrm{MHz}$ & 36.54 \\
\hline 6 & $2.250 \mathrm{MHz}$ & 34.12 \\
\hline 7 & $2.500 \mathrm{MHz}$ & 32.52 \\
\hline 8 & $2.750 \mathrm{MHz}$ & 31.1 \\
\hline 9 & $3.000 \mathrm{MHz}$ & 30.62 \\
\hline 10 & $3.250 \mathrm{MHz}$ & 29.01 \\
\hline 11 & $3.500 \mathrm{MHz}$ & 28.57 \\
\hline 12 & $3.750 \mathrm{MHz}$ & 275 \\
\hline Ket: & $:$ Frekuensi Downclocking \\
& $:$ Frekuensi Standar & \\
& $:$ Frekuensi Overclocking & \\
\hline
\end{tabular}

Gambar 5. Perbandingan kinerja dengan frekuensi standar pada desktop dengan aplikasi Windows Boot Timer

Sedangkan uji aplikasi Benchmark Real Life pada Winrar untuk mengetahui hasil perbandingan waktu kinerja antara frekuensi standar dengan frekuensi pada saat downclocking dan overclocking dapat dilihat pada gambar berikut.

\begin{tabular}{|c|c|c|c|c|}
\hline Frekuensi & $\begin{array}{l}\text { Suhu Core } \\
1 \text { idle (c) }\end{array}$ & $\begin{array}{l}\text { Suhu Core } 2 \\
\text { idle (c) }\end{array}$ & $\begin{array}{c}\text { Suhu core } 1 \text { full } \\
\text { load (c) }\end{array}$ & $\begin{array}{c}\text { Suhu core } 2 \text { full } \\
\text { load (c) }\end{array}$ \\
\hline $1.000 \mathrm{MHz}$ & $37.4^{0}$ & $34.4^{0}$ & $42^{\circ}$ & $38.4^{0}$ \\
\hline $1.250 \mathrm{MHz}$ & $38^{\circ}$ & $35.6^{\circ}$ & $45.4^{\circ}$ & $42.4^{0}$ \\
\hline $1.500 \mathrm{MHz}$ & $38.8^{0}$ & $35.8^{\circ}$ & $47^{0}$ & $44.4^{0}$ \\
\hline $1.750 \mathrm{MHz}$ & $39^{\circ}$ & $36^{\circ}$ & $48.1^{0}$ & $45.8^{0}$ \\
\hline $2.000 \mathrm{MHz}$ & $40^{\circ}$ & $36.2^{0}$ & $48.5^{\circ}$ & $46^{\circ}$ \\
\hline $2.250 \mathrm{MHz}$ & $40.8^{0}$ & $36.8^{\circ}$ & $49^{0}$ & $47.2^{0}$ \\
\hline $2.500 \mathrm{MHz}$ & $41^{0}$ & $37^{0}$ & $50.6^{0}$ & $48.1^{\circ}$ \\
\hline $2.750 \mathrm{MHz}$ & $42.4^{0}$ & $39.2^{0}$ & $52.1^{0}$ & $49^{0}$ \\
\hline $3.000 \mathrm{MHz}$ & $43.6^{0}$ & $40^{\circ}$ & $53.1^{0}$ & $50.2^{0}$ \\
\hline $3.250 \mathrm{MHz}$ & $44^{\circ}$ & $44.2^{0}$ & $57.3^{0}$ & $52.6^{\circ}$ \\
\hline $3.500 \mathrm{MHz}$ & $45^{\circ}$ & $45.1^{0}$ & $60^{\circ}$ & $53.6^{0}$ \\
\hline Ket: & 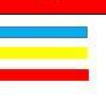 & $\begin{array}{l}\text { Frekuensi D } \\
\text { Frekuensi } \\
\text { : Frekuensi }\end{array}$ & $\begin{array}{l}\text { ownclocking } \\
\text { andar } \\
\text { verclocking }\end{array}$ & \\
\hline
\end{tabular}

Gambar 6. Perbandingan kinerja dengan frekuensi standar pada desktop dengan aplikasi Winrar

Perbandingan Suhu antara frekuensi standar dengan frekuensi pada saat downclocking dan overclocking ditunjukkan dalam gambar berikut. 


\begin{tabular}{|c|c|c|}
\hline Frekuensi & Idle (W) & Full Load (W) \\
\hline $1.000 \mathrm{MHz}$ & 34.4 & 36 \\
\hline $1.250 \mathrm{MHz}$ & 35.6 & 38.8 \\
\hline $1.500 \mathrm{MHz}$ & 35.8 & 39 \\
\hline $1.750 \mathrm{MHz}$ & 36 & 40 \\
\hline $2.000 \mathrm{MHz}$ & 36.2 & 40.8 \\
\hline $2.250 \mathrm{MHz}$ & 36.8 & 41 \\
\hline $2.500 \mathrm{MHz}$ & 37 & 42.4 \\
\hline $2.750 \mathrm{MHz}$ & 39.2 & 43.6 \\
\hline $3.000 \mathrm{MHz}$ & 40 & 44 \\
\hline $3.250 \mathrm{MHz}$ & 44.2 & 45 \\
\hline $3.500 \mathrm{MHz}$ & 45.1 & 46 \\
\hline
\end{tabular}

Gambar 7. Perbandingan kinerja dengan frekuensi standar pada pengukuran suhu

\section{Kesimpulan}

Frekuensi downcloking yang dihasilkan sebesar $1000 \mathrm{MHz}$, Frekuensi standar 3000 $\mathrm{MHz}$, frekuensi overclocking sebesar $3.750 \mathrm{MHz}$. Pada frekuensi overclock kinerja dari prosesor lebih baik dan cepat dan sebaliknya pada frekuensi downclock kinerja prosesor lebih lambat. Dengan dilakukannya overclock sistem akan tidak stabil hingga terjadi lag/hang. Sistem tidak stabil terjadi pada frekuensi di atas $3,75 \mathrm{GHz}$. Adanya peningkatan frekuensi kinerja meyebabkan perangkat lebih cepat panas dan jika terjadi terus menerus dimungkinkan akan terjadi overheat.

\section{Referensi}

[1] S. Mueller, Upgrading and Repairing PCs: Upgrading and Repairing_c22. Que Publishing, 2015.

[2] M. Nazir, "Metode Penelitian, Cetakan Ke Tujuh," Bogor Penerbit Ghalia Indones., 2011.

[3] S. Wainner and R. Richmond, The book of overclocking: tweak your PC to unleash its power. No Starch Press, 2003.

[4] S. William, "Organisasi dan Arsitektur Komputer," Kelompok Gramedia, 2003.

[5] A. Yani, "Panduan Menjadi Teknisi Komputer (utk teknisi, hobiis, \& pemula) Surabaya: PT," Kawan Pustaka, 2011.

[6] E. Nugroho, "Pengenalan Komputer." Yogyakarta: Andi Offset, 1990. 